\title{
Article \\ Specific Mycoparasite-Fusarium Graminearum Molecular Signatures in Germinating Seeds Disabled Fusarium Head Blight Pathogen's Infection
}

\author{
Seon Hwa Kim ${ }^{1}{ }^{\oplus}$, Rachid Lahlali ${ }^{2,3}$, Chithra Karunakaran ${ }^{2}$ and Vladimir Vujanovic ${ }^{1, *}$ \\ 1 Department of Food and Bioproduct Sciences, University of Saskatchewan, 51 Campus Drive, \\ Saskatoon, SK S7N 5A8, Canada; sek049@mail.usask.ca \\ 2 Canadian Light Source, 44 Innovation Blvd, Saskatoon, SK S7N 2V3, Canada; \\ rlahlali@enameknes.ac.ma (R.L.); chithra.karunakaran@lightsource.ca (C.K.) \\ 3 Department of Plant Protection, Phytopathology Unit, Ecole Nationale d'Agriculture de Meknès, BP/S 40, \\ Meknès 50001, Morocco \\ * Correspondence: vladimir.vujanovic@usask.ca
}

check for updates

Citation: Kim, S.H.; Lahlali, R.; Karunakaran, C.; Vujanovic, V. Specific Mycoparasite-Fusarium Graminearum Molecular Signatures in Germinating Seeds Disabled Fusarium Head Blight Pathogen's Infection. Int. J. Mol. Sci. 2021, 22, 2461. https://doi.org/10.3390/ ijms22052461

Academic Editor: George Komis

Received: 28 January 2021

Accepted: 25 February 2021

Published: 28 February 2021

Publisher's Note: MDPI stays neutral with regard to jurisdictional claims in published maps and institutional affiliations.

Copyright: (c) 2021 by the authors. Licensee MDPI, Basel, Switzerland. This article is an open access article distributed under the terms and conditions of the Creative Commons Attribution (CC BY) license (https:/ / creativecommons.org/licenses/by/ $4.0 /)$.

\begin{abstract}
Advances in Infrared (IR) spectroscopies have entered a new era of research with applications in phytobiome, plant microbiome and health. Fusarium graminearum 3-ADON is the most aggressive mycotoxigenic chemotype causing Fusarium head blight (FHB) in cereals; while Sphaerodes mycoparasitica is the specific Fusarium mycoparasite with biotrophic lifestyle discovered in cereal seeds and roots. Fourier transform infrared (FTIR) spectroscopy analyses depicted shifts in the spectral peaks related to mycoparasitism mainly within the region of proteins, lipids, also indicating a link between carbohydrates and protein regions, involving potential phenolic compounds. Especially, S. mycoparasitica contributes to significant changes in lipid region $3050-2800 \mathrm{~cm}^{-1}$, while in the protein region, an increasing trend was observed for the peaks $1655-1638 \mathrm{~cm}^{-1}$ (amide I) and $1549-1548 \mathrm{~cm}^{-1}$ (amide II) with changes in indicative protein secondary structures. Besides, the peak extending on the region $1520-1500 \mathrm{~cm}^{-1}$ insinuates a presence of aromatic compounds in presence of mycoparasite on the F. graminearum root sample. Monitoring shift in improved seed germination, fungus-fungus interface through scanning electron microscopy (SEM) and confocal laser scanning microscopy (CLSM), and FTIR molecular signatures combined with principal component analysis (PCA) proved useful tools to detect an early mycoparasitism as a vital asset of the preventive biocontrol strategy against plant pathogens.
\end{abstract}

Keywords: seeds; fourier transform infrared (FTIR); interactome; mycoparasitism; Fusarium graminearum; fusarium head blight (FHB); biocontrol; Sphaerodes mycoparasitica

\section{Introduction}

Across plants, host-associated microbiomes play a vital role in shaping host defense via regulating expressions of resistance genes and plant health. Seed or grain, known as kernel in wheat, is considered as a plant reproductive unit that harbors a core microbiome essential for seed germination, plant growth and reproduction under stress [1]. Agrifood system is using elite seed lines for the staple crop establishment and production to maximize yield - the primary food source for the human population [2]. As such, seed is becoming a subject of increasing interest to an early control of fungal pathogens, molds and mycotoxins in crops leading to the creation of the "plant prenatal care" concept [3]. Seed harbors two distinct functional groups of fungal populations, named beneficial biocontrol and plant pathogenic agents. Healthy seeds are essential for the optimal crop growth and yield, but seed-borne pathogens such as Fusarium spp. may reduce seed vitality, germination, and cause damping-off disease of seedlings. In cereals, Fusarium head blight (FHB) caused by Fusarium graminearum (F. graminearum) can severely impact seed quality and limit the 
availability of seed [4]. In other hand, the fungal antagonists including mycoparasitic fungi [5] and mycoparasitism-related genes [6-8] have tremendous potential in controlling Fusarium and improving plant protection. Hence, the global food security research is seeking for mycoparasites microorganisms as ecofriendly biocontrol strategies to reduce Fusarium damages on seed and minimize mycotoxins in staple cereal foods [9]. The particular focus is on the suppression of Fusarium infectious process. The FHB disease curve starts during seed germination and progresses during anthesis, grain development and seed dispersion. The first is a critical developmental stage when an early biocontrol of seed-born Fusarium can be also protective to reduce mycotoxins in crops. The biocontrol approach-based on mycoparasitism is attracting more attention among agri-food, human and animal health scientists [10]. It is a promising tool to reduce the use of synthetic chemicals in staple crop by providing prenatal care to plant.

Traditionally, phytoprotection is seeking for biocontrol solutions [11] deemed appropriate to manage seed-born Fusarium diseases and outbreaks while protecting the environment and food safety without genetically engineered plants. However, it is likely that the spectrum of studied mycoparasites against Fusaria and related FHB symptoms in cereals has been limited to Trichoderma and Clonostachys fungal generalists, although these non-specific mycoparasites have not yet achieved an economically and environmentally sustainable control perspective [12]. Recently, biocontrol science shifted from these non-specific to specific biocontrol fungal agents such as mycoparasitic Ampelomyces against powdery mildew (Erysiphales) and Sphaerodes against Fusaria pathogens and mycotoxins in cereal grain [13]. The term mycoparasitic lifestyle can be defined as a parasitic fungus-fungus relationship, in which the mycoparasite interacts with the fungus-host cell to perform its biological cycle in interaction with plant-host tissue [14]; the interaction involves several signaling pathways to ensure a mycoparasite's biocontrol effectiveness.

Sphaerodes mycoparasitica is owning its biotrophic mycoparasitic lifestyle on parasitic Fusarium hosts, while its mechanism of mycoparasitism at molecular level has not yet been established. As a result, molecular studies of these biocontrol fungus as other obligate mycoparasites (e.g., Ampelomyces) are seriously lagging behind those of necrotrophic biocontrol generalists (e.g., Clonostachys, Trichoderma). In addition to biocontrol, S. mycoparasitica proved endosymbiotic plant growth promoting ability in enhancing wheat seed germination [14]. However, the endophytic mycoparasitism is often regulated by a combination of intrinsic and extrinsic factors. Intrinsic-genomic, transcriptomic and metabolomic factors may have an important role in the specific biocontrol of the plant pathogenic Fusarium in wheat seed [1,12]. Recent Fourier transform infrared (FTIR) work has drawn fascinating connections between fungal endophyte-wheat seed interaction changes under stress-drought conditions shedding more light on biological wheat seed stratification and mycovitality [15]. The mycovitality (vitalitas = 'life-force') defines plant performance in a continuum with mycotrophy (trophe = 'nutrition'). Through mycovitality (endophyte-seed association), endosymbiotic inoculants, via coleorhiza-driven seed stratification, were shown to regulate wheat's (Triticeae) phytohormones, enhancing crop hardiness to environmental stressors. Previous results also demonstrated the ability of S. mycoparasitica to promote wheat seed germination under in vitro conditions. This prenatal care concept taking into consideration seed-related plant growth promotion (PGP) and biocontrol has piqued the interest of the global food security scientists, as the synergy of the two mechanisms in endophytic mycoparasites is remaining unexplored. It's particularly true in terms of seed-health potential linked to the mycoparasite-Fusarium interacting molecules during early events of Fusarium suppression on seed germinants. To accurately measure the practical outcomes of the mycoparasitism, one should consider the effectiveness of mycoparasite relative to cell-to-cell interaction between the mycoparasite- the plant pathogenic host and-the plant host at the tissue and molecular level. Hence, we hypothesized that $S$. mycoparasitica positively shapes a profile of plant protective molecular signatures in germinating cereal seed-radicle cells, thus suppressing FHB pathogen in its early stage of host infection. 
The biocontrol agents that regulate wheat kernel metabolites against Fusarium graminearum are still poorly characterized. In the past decade, several metabolomics attempts have been made to decipher the chemical defense that cereals employ to counteract F. graminearum [16,17]. Although some major classes of metabolites have been highlighted (e.g., amino acids; carbohydrates; fatty acids; organic acids, phenylpropanoids and terpenoids) $[17,18]$, the knowledge remains partial when comes to the integrated network of chemicals in cereal kernels stimulated by biological control agents [19]. Recently, FTIR revealed the beneficial fungus-dependent components changes in kernel through germinating kernel-fungus interaction under abiotic stress [15] opening new horizons for research on the kernel-beneficial fungus chemical profile or orchestrated metabolites to resist to F. graminearum as a biotic stress.

The FTIR spectroscopy has demonstrated its usefulness as a quick, reliable and valuable technique to depict the presence of functional groups of compounds identification $[20,21]$ in heterogeneous biological samples including grain, pollen, coleorhiza, plants, soils and microorganisms [15,21-23]. Therefore, the scanning electron microscopy (SEM) and confocal laser scanning microscopy (CLSM) coupled with FTIR (mid-infrared) spectroscopy analytical methods were employed to elucidate seed structural tissue and metabolome responses to F. graminearum colonization under pathogen conductive (normal) versus suppressive (mycoparasite) interactive conditions. Quantifying metabolic shift in the seed tissues of Triticum host germinant is essential for understanding the mycoparasitic effect of S. mycoparasitica during seed germination together with shifts in interactome profile associated to reduce Fusarium infection/attack on seed germinants. The FTIR spectroscopy allows monitoring of compositional changes in cells/tissues (components) by detecting functional groups of different compounds.

Investigation of FTIR biochemical composition changes in wheat seed radicles (primary roots) may predict plant response to the capacity of $S$. mycoparasitica against $F$. graminearum 3-ADON. Further, mapping the expression of key signatory molecules within tripartite mycoparasite-Fusarium-plant host interactions may further elucidate the mechanisms of mycoparasitism by which mycoparasite improves host traits and control Fusarium to secure a prenatal health in cereal host. The overall goal is to generate fundamental knowledge on tripartite seed endosymbiosis and mycoparasitism related interactome traits, thus creating a tool to depict early biochemical signatures for improved crop stress resilience to plant pathogens and mycotoxins.

\section{Results and Discussion}

\subsection{In Vitro Wheat Seed Germination and Growth}

S. mycoparasitica showed the protective effect on the seed by maintaining seed vigor and suppressing the growth of F. graminearum compared to the seed of the F. graminearum treatment only (Figure 1A-F). There was no symptomatic, necrotic root or coleoptile rot, samples associated with Fusarium infection observed in the seed surrounded by S. mycoparasitica seed during 2-day incubation. The control seeds were also healthy. 


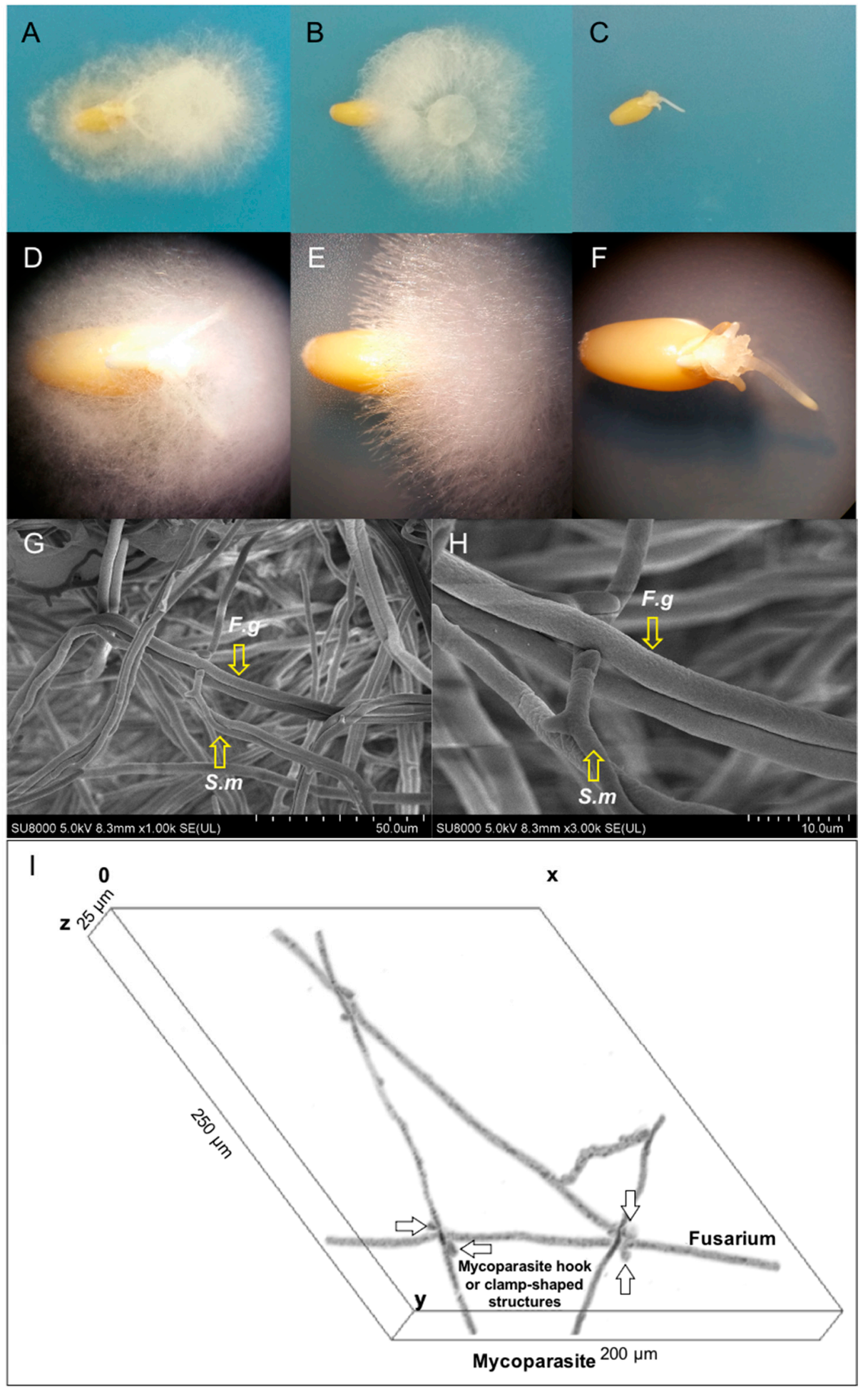

Figure 1. In vitro root and coleoptile growth of 2 days-old wheat kernel (seed) germinant (Triticum turgidum L. ssp. durum (Desf.)) under the different biotic conditions. (A,D), the seed surrounded by S. mycoparasitica (left side mycelium) against F. graminearum (right side mycelium); (B,E), the seed faced with F. graminearum; (C,F), the non-treated seed (control). The coleoptile and radicle of the mycoparasite treatment against $F$. graminearum were clearly visible compared with that of the Fusarium treatment. (G) (scale: $50 \mu \mathrm{m}$ ) and (H) (scale: $10 \mu \mathrm{m})$, SEM of the fungal interface between the mycoparasite (S. mycoparasitica) and F. graminearum interactive hyphae. (I). CLSM-tridimensional $(\mathrm{X}=200 \mu \mathrm{m} \times \mathrm{Y}=250 \mu \mathrm{m} \times \mathrm{Z}=25 \mu \mathrm{m})$ view of the "triangular" S. mycoparasitica-F. graminearum hyphal network in which mycoparasitic hook- or clamp-shaped infective structure (arrows) attacks on Fusarium hyphae. 
The protective effect of the mycoparasite for the seed could be derived from the mycoparasitic interaction with the host for which evidently, S. mycoparasitica and F. graminearum interactive hyphae were observed on SEM (Figure 1G,H). In Figure 1I, the CLSMtridimensional view depicted S. mycoparasitica hyphal network-a formation of the protective "shield" surrounding F. graminearum hyphae. The fungus-fungus interface is formed $\sim 1 \mathrm{~mm}$ distance from the seed surface; it is characterized by "triangular" S. mycoparasitica- $F$. graminearum hyphal network in which mycoparasitic hook- or clamp-shaped infective structure attacks on Fusarium hyphae. This early step in mycoparasitism allowed S. mycoparasitica to suppress the progress of $F$. graminearum pathogenic hyphae towards seed-host tissue. Furthermore, the epiphytic S. mycoparasitica hyphae on seed coat followed by endophytic colonization of seed germinant [1-2day] allowed promotion of seed germination and growth, respectively, as previously described by Vujanovic and Goh [14]. As shown in Figure 2, the germination (\%) of the seed surrounded by S. mycoparasitica against F. graminearum was significantly higher $(87.5 \%)$ than that $(75 \%)$ of the seed faced by $F$. graminearum only at day 2 . The non-treated seed (control) showed $100 \%$ germination. This shift in phenotypic and biological/behavioral traits in germinating seed, induced by the mycoparasite on the F. graminearum root samples (Figure 1), was also analyzed by its contribution to the associated changes in FTIR molecular signatures (Figure 3).

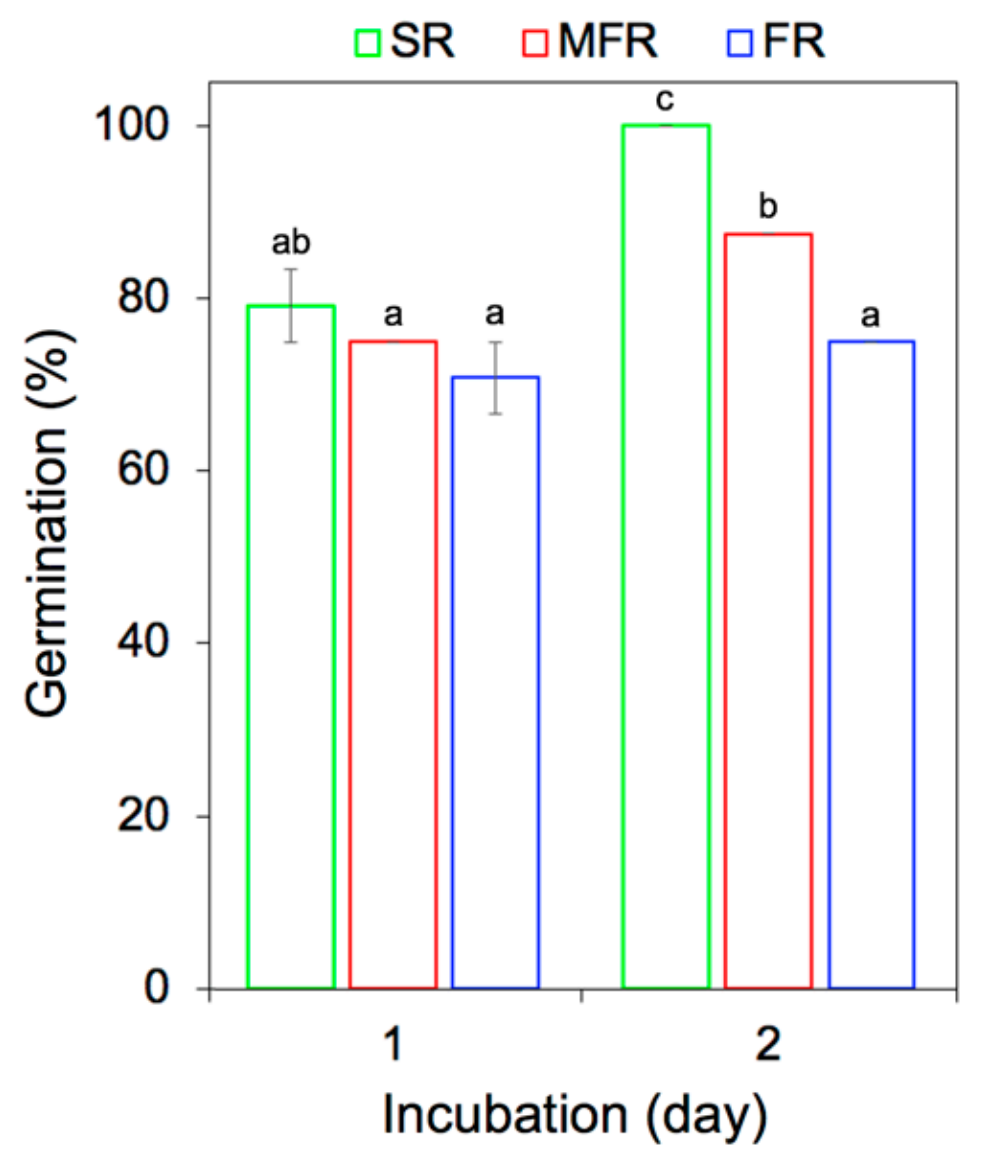

Figure 2. In vitro seed germination (\%) under the different biotic conditions. The seed surrounded by the mycoparasite $S$. mycoparasitica against F. graminearum (MFR, red square line); the seed infected by F. graminearum (FR, blue square line); the non-treated or non-infected seed (SR, green square line). The germination (\%) was calculated by the ratio of the number of germinated seeds for each treatment over the number of germinated seeds at day 2 control multiplied by 100 . The presented bars are means of three sets of germination (\%) with standard errors. The different letters $(\mathrm{a}-\mathrm{c})$ indicate statistically significant differences $(p<0.05)$ according to Tukey's honestly significant difference test. 


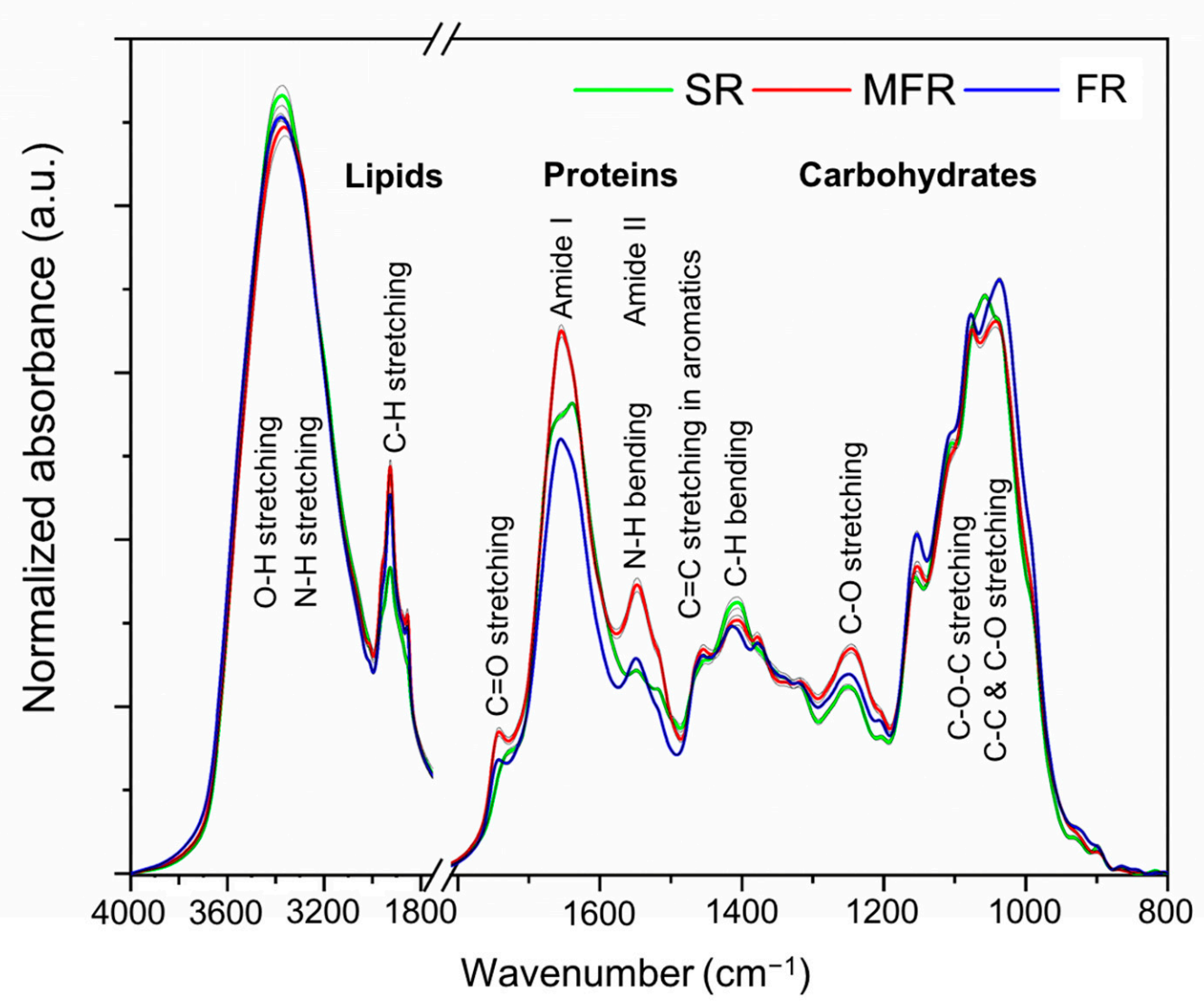

Figure 3. The vector normalized and average FTIR spectra of the root samples collected from germinating seeds (two-day-old) surrounded by S. mycoparasitica against F. graminearum (MFR, red line); the seed infected by F. graminearum (FR, blue line); the non-treated or non-infected seed (SR, green line). Data are means of vector normalized 6 spectra for each treatment and standard errors are shown as black lines.

\subsection{FTIR Spectra}

2.2.1. Implication of Biochemical Changes in the Root Composition of Wheat Seed

FTIR spectroscopy profile depicted considerable differences of the germinating seedroot samples when treated with fungi (FR-virulent F. graminearum 3-ADON alone); (MFRmycoparasitic $S$. mycoparasitica + virulent $F$. graminearum 3-ADON) compared to the samples of the roots (SR) without any fungal inoculation (control). The baseline corrected normalized FTIR spectra of the root samples in the range 4000-800 wavenumber $\left(\mathrm{cm}^{-1}\right)$ are shown in Figure 3. The biochemical FTIR profiles of the root samples are represented by characteristic peaks for lipids, proteins, and carbohydrates mainly in the spectral regions $3050-2800 \mathrm{~cm}^{-1}, 1800-1200 \mathrm{~cm}^{-1}$, and $1200-800 \mathrm{~cm}^{-1}$, respectively. The tentative assignment of the characteristic peaks representing different functional groups of potentially possible components or compounds were summarized in Table 1. It is important note that the peak position (at wavenumber), intensity, and shape were not accurately matched with the data of the references mainly due to the different samples affecting the vibrational modes, but the major and typical characteristics for the peaks were applied to the tentative assignment for this study. For the sample comparisons, the term "intensity" was referred as a semiquantitative manner.

On the normalized spectra in Figure 3, the broad and strong peaks at about $3430-3300 \mathrm{~cm}^{-1}$ with a maximum range between $3379-3366 \mathrm{~cm}^{-1}$ were observed and assigned to $\mathrm{NH}$ stretching of amines from proteins and $\mathrm{OH}$ stretching of alcohols that might be derived from carbohydrates (including cellulose, hemicelluloses, starch, and fructans), glycoconjugates or glycomolecules (e.g., arabinogalactan proteins and extensins belonging to the superfamily of hydroxyproline- 
rich glycoproteins constituting approximately $10 \%$ of the dry weight of plant cell wall) [36], and metabolites related to root formation/development and plant defense responses. The peak at $3372 \mathrm{~cm}^{-1}$ in the control (SR) was more intense than that of fungal treatments (FR > MFR; the integrated absorption peak for MFR was significantly reduced shown in Table 2) and slightly shifted in both MFR (to $3366 \mathrm{~cm}^{-1}$ ) and FR (to $3379 \mathrm{~cm}^{-1}$ ), implying that there might be changes in the hydrogen bonds among the root components (including potentially proteins, carbohydrates, and glycoconjugates) or variations in combinations of root components during the interactions with the different fungi which might be linked to plant interactive or defense responses.

Table 1. The tentative assignment of FTIR absorption peaks of wheat root samples-based on literature (Web of Science) data (see references). The wavenumbers presented in the table are the ranges for the mean values of the control and fungal treatments.

\begin{tabular}{|c|c|c|c|}
\hline Wavenumber $\left(\mathrm{cm}^{-1}\right)$ & $\begin{array}{c}\text { Vibration Modes of Functional } \\
\text { Groups }\end{array}$ & Probable Components & References \\
\hline $3430-3300$ & $\begin{array}{c}\text { O-H stretching of Alcohols and } \\
\text { carboxylic acids } \\
\mathrm{N}-\mathrm{H} \text { stretching of amide A }\end{array}$ & $\begin{array}{c}\text { Carbohydrates (cellulose, hemicelluloses) } \\
\text { and Glycoconjugates } \\
\text { Proteins (amide A) }\end{array}$ & {$[24,25]$} \\
\hline $\begin{array}{l}2927-2924 \\
2856-2853\end{array}$ & $\begin{array}{l}\text { C-H stretching of asymmetric and } \\
\text { symmetric } \mathrm{CH}_{2}\end{array}$ & Lipids & {$[24,25]$} \\
\hline $1744-1700$ & $\begin{array}{l}\mathrm{C}=\mathrm{O} \text { stretching of aldehyde, ketone, } \\
\text { ester compounds, and carboxylic acid }\end{array}$ & $\begin{array}{c}\text { Fatty acids, aliphatic and aromatic } \\
\text { carbonyl compounds } \\
\text { hemicelluloses, lignins, } \\
\text { pectins }\end{array}$ & [24-26] \\
\hline $1655-1638$ & $\mathrm{C}=\mathrm{O}$ stretching of $-\mathrm{CO}-\mathrm{NH}$ & Proteins (amide I) & [27] \\
\hline $1549-1548$ & $\mathrm{~N}-\mathrm{H}$ bending and $\mathrm{C}-\mathrm{N}$ stretching & Proteins (amide II) & [27] \\
\hline $1520-1500$ & $\mathrm{C}=\mathrm{C}$ stretching of aromatic rings & $\begin{array}{l}\text { Lignin related molecules; ferulic acid and } \\
\text { aromatic ring containing compounds }\end{array}$ & {$[24,28,29]$} \\
\hline $1456-1453$ & $\mathrm{C}-\mathrm{H}$ bending of $\mathrm{CH}_{2}$ and $\mathrm{CH}_{3}$ & Proteins and lipids & {$[30,31]$} \\
\hline $1319-1318$ & $\begin{array}{l}\mathrm{C}-\mathrm{N} \text { stretching and } \mathrm{N}-\mathrm{H} \text { deformation or } \\
\text { more complex vibrations }\end{array}$ & Proteins (amide III) & {$[32]$} \\
\hline $1250-1246$ & $\begin{array}{c}\text { C-O stretching } \\
\text { Asymmetric } \mathrm{P}=\mathrm{O} \text { stretching }\left(\text { of } \mathrm{PO}^{2-}\right)\end{array}$ & $\begin{array}{c}\text { Hemicellulose, } \\
\text { Phospholipids and nucleic acids }\end{array}$ & {$[24,27,30,33]$} \\
\hline $\begin{array}{l}1157-1153 \\
1077-1076\end{array}$ & $\begin{array}{l}\text { Mainly C-O-C asymmetric stretching } \\
\text { and C-O stretching } \\
\text { Symmetric stretching of } \mathrm{PO}^{2-}\end{array}$ & $\begin{array}{c}\text { Mainly } \\
\text { Cellulose, } \\
\text { Phospholipids and nucleic acids }\end{array}$ & {$[24,27,30,33]$} \\
\hline $1058-1036$ & $\begin{array}{c}\text { C-O-C symmetric stretching and } \\
\text { C-C, } \mathrm{C}-\mathrm{O} \text { stretching or } \mathrm{C}-\mathrm{OH} \text { bending }\end{array}$ & $\begin{array}{l}\text { Mainly Cellulose, } \\
\text { hemicellulose }\end{array}$ & {$[24,27,34,35]$} \\
\hline
\end{tabular}

The observed peaks in the region between $3050-2800 \mathrm{~cm}^{-1}$ were assigned to $\mathrm{CH}_{2} / \mathrm{CH}_{3}$ stretching of mainly lipids which broadly could include all components with aliphatic portions such as (membrane) lipids, lipid-derived molecules, fatty acids, and waxes (e.g., suberin and/or cuticular components) [37]: - $\mathrm{CH}$ stretching at $3014 \mathrm{~cm}^{-1}$ acyl lipids; asymmetric and symmetric $\mathrm{CH}_{3}$ stretching of mainly lipids at $2961 \mathrm{~cm}^{-1}$ and $2873 \mathrm{~cm}^{-1}$; asymmetric and symmetric $\mathrm{CH}_{2}$ stretching of mainly lipids at $2927-2924 \mathrm{~cm}^{-1}$ and $2856-2853 \mathrm{~cm}^{-1}$; $\mathrm{CH}_{2} / \mathrm{CH}_{3}$ bending (deformation) of mainly lipids (alkanes) and proteins at $1456-1453 \mathrm{~cm}^{-1}$; $\mathrm{C}=\mathrm{O}$ stretching of carbonyl compounds at $1744-1700 \mathrm{~cm}^{-1}$ which may contain fatty acids, phospholipids, phytosterol esters, alkyl esters (related to pectins, hemicelluloses, and lignins), and any other aliphatic and aromatic carbonyl compounds. In particular, the ester linkage may be derived from the carboxylic groups of the $p$-coumaric- and ferulic acids for the hemicellulose and/or lignin [38]. The intensity of the peaks in this region (3050-2800 $\left.\mathrm{cm}^{-1}\right)$ was increased significantly in the fungal treatments (more prominent in MFR than FR, but the 
integrated peak areas of MFR and FR for this region were not significantly different) when compared with the control (Table 2), which may reflect increased production of lipids such as phospholipids, glycolipids (mainly galactolipids), and sphingolipids (mainly composed of glycosyl-inositolphosphoceramides) located in the plasma membrane and lipid-derived metabolites of the plant host during plant-microbe interactions related to plant immune signaling [39-41]. In addition, in the case of the peak at $3014 \mathrm{~cm}^{-1}$, the shape of the peak was relatively noticeable in MFR than FR compared to the control (SR), although the observed peak was weak which may indicate the presence of unsaturated fatty acid chains (derived from the fungi directly) [29].

Table 2. Integrated absorption peaks for the FTIR spectra of the root samples collected from 2-day-old germinating seeds and esterification (\%).

\begin{tabular}{|c|c|c|c|c|}
\hline \multirow{2}{*}{$\begin{array}{l}\text { Peak Position }\left(\mathrm{cm}^{-1}\right) \\
\text { with Relative Identity }\end{array}$} & \multicolumn{4}{|c|}{ Integrated Absorption Peak } \\
\hline & $\begin{array}{l}\text { Wavenumber } \\
\text { Range }\left(\mathrm{cm}^{-1}\right)\end{array}$ & SR & MFR & FR \\
\hline $\begin{array}{c}\text { 3430-3300 } \\
\text { OH stretching and Amide }\end{array}$ & $3680-3000$ & $19.58 \pm 0.02^{b}$ & $19.18 \pm 0.12^{\mathrm{a}}$ & $19.54 \pm 0.03^{b}$ \\
\hline $\begin{array}{l}2927-2924 \\
2856-2853 \\
\text { Lipids }\end{array}$ & $3000-2800$ & $2.73 \pm 0.06^{\mathrm{a}}$ & $3.11 \pm 0.06^{b}$ & $2.96 \pm 0.02^{b}$ \\
\hline $\begin{array}{c}1744-1743 \\
\text { Carbonyl }\end{array}$ & $1760-1720$ & $0.23 \pm 0.00^{\mathrm{a}}$ & $0.30 \pm 0.01^{b}$ & $0.24 \pm 0.00^{\mathrm{a}}$ \\
\hline $\begin{array}{l}\text { 1655-1638 } \\
\text { Amide I }\end{array}$ & $1700-1620$ & $1.92 \pm 0.01^{\mathrm{b}}$ & $2.06 \pm 0.03^{c}$ & $1.69 \pm 0.00^{\mathrm{a}}$ \\
\hline $\begin{array}{c}\text { 1549-1548 } \\
\text { Amide II }\end{array}$ & $1560-1530$ & $0.35 \pm 0.00^{\mathrm{a}}$ & $0.49 \pm 0.01^{\mathrm{b}}$ & $0.37 \pm 0.00^{\mathrm{a}}$ \\
\hline $\begin{array}{c}\mathrm{1518}-1516 \\
\mathrm{C}=\mathrm{C} \text { stretching of } \\
\text { aromatic rings }\end{array}$ & $1520-1500$ & $0.21 \pm 0.00^{b}$ & $0.23 \pm 0.01^{\mathrm{c}}$ & $0.18 \pm 0.00^{\mathrm{a}}$ \\
\hline Esterification (\%) ${ }^{1}$ & & $10.70 \pm 0.05^{\mathrm{a}}$ & $12.56 \pm 0.08^{b}$ & $12.47 \pm 0.05^{b}$ \\
\hline $\begin{array}{l}\text {, control seed not affected by } \mathrm{f} \\
\text {, seed infected by Fusarium gra } \\
\text { fferent letters }\left({ }^{\mathrm{a}-\mathrm{c}} \text { ) along the ro }\right. \\
\text { st. }{ }^{1} \text { Esterification (\%) was calc } \\
\text { d } 1655-1638 \text { and then express }\end{array}$ & $\begin{array}{l}\text { i; MFR, seed sur } \\
\text { earum. Each valı } \\
\text { are significantly } \\
\text { ed by the peak }\end{array}$ & $\begin{array}{l}\text { nded by the my } \\
\text { expressed as } m \\
\text { erent }(p<0.05) b \\
4-1743) \text { dividec }\end{array}$ & $\begin{array}{l}\text { arasite against } F u \\
\pm \text { standard error } \\
\text { skey's honestly s } \\
\text { the sum of peak }\end{array}$ & $\begin{array}{l}\text { arium graminearum } \\
(n=6) \text {. Values with } \\
\text { gnificant difference } \\
\text { reas for } 1744-1743\end{array}$ \\
\hline
\end{tabular}

The presence of carbonyl compounds (e.g., pectins or pectic polysaccharides which are ubiquitous polysaccharides in plants; usually more found in roots than leaves) was expected due to $\mathrm{C}=\mathrm{O}$ stretching. However, the control showed no clear peak at this region. Importantly, there was the obvious peak at $1744 \mathrm{~cm}^{-1}$ for MFR with the outstanding appearance and at $1743 \mathrm{~cm}^{-1}$ for FR (the integrated absorption peak of MFR was significantly higher than that of FR and SR shown in Table 2), implying the heterogeneity of the chemical structures of the carbonyl compounds which could be affected by conjugation with the ester single-bonded oxygen and may extend the variety of possible root cellular components including fatty acids, aliphatic and aromatic carbonyl compounds, hemicelluloses, and lignins, not just subjective to the pectins. It was supportive that the esterification (\%) used to evaluate the degree of esterification to which the ratio of the peak areas for $\mathrm{C}=\mathrm{O}$ stretching over the sum of the peak areas for $\mathrm{C}=\mathrm{O}$ stretching and amide I was supposed to be proportional [21] was significantly higher in MFR and FR than in SR (Table 2).

Apart from the peaks for $\mathrm{OH}$ and NH stretching (around $3430-3300 \mathrm{~cm}^{-1}$ ), the relatively prominent peak was observed at $1655-1638 \mathrm{~cm}^{-1}$ assigned to protein amide I attributable to $(\mathrm{C}=\mathrm{O}$ stretching from $-\mathrm{CO}-\mathrm{NH})$, along with the peak at $1549-1548 \mathrm{~cm}^{-1}$ assigned to amide II (attributable to N-H bending and C-N stretching) and the peak (at 
$1319-1318 \mathrm{~cm}^{-1}$ ) assigned to amide III (resulted from more complex vibrational modes than amide I and II) [32]. The intensity of the three peaks derived from proteins in MFR was higher than that of SR or FR (MFR > SR > FR for amide I; MFR > FR > SR for amide II; MFR $>$ FR $>$ SR for amide III). Particularly, the integrated absorption peaks for the amide I and II were significantly greater in MFR than in SR or FR (Table 2), implying the probable proteins were more affected by the mycoparasite. Noticeably, the control showed a different peak shape with the peak center shifted to $1638 \mathrm{~cm}^{-1}$, compared to fungal treatments. This difference in the peak shape may reveal the appearance of different protein secondary structures such as $\alpha$-helices (at 1655), $\beta$-turns (at 1675), and $\beta$-sheets (at 1633) [42,43]. It seemed that the control tended to have higher $\beta$-sheets (at 1633) among the possible protein secondary structures, whereas the fungal treatments tended to have higher $\alpha$-helices (at 1655) of them. The variation of protein secondary structures corresponded to the previous findings of Lahlali et al. [24] who reported that the susceptible cultivar showed an increase in $\alpha$-helices and a decrease in $\beta$-sheets responding to the pathogen, which may imply plant resistance responses to stress through regulation of phenylpropanoid and lignin biosynthesis [24].

With relation to lignin, it seemed that the control sample had the relatively noticeable peak shape at $1518 \mathrm{~cm}^{-1}$ compared to fungal treatments. MFR showed a broad shoulder shape at this region $\left(1520-1500 \mathrm{~cm}^{-1}\right)$ which may be attributable to $C=C$ stretching of aromatic rings in lignin [24], ferulic acid [28], and an aromatic ring containing amino acids (e.g., tyrosine) [29]. At this region, the integrated absorption peak was higher in MFR than in SR or FR (Table 2). Presumably, the region between $1520-1300^{-1}$ may contain any other aromatic compounds due to the complex absorption profiles. Especially, MFR tended to show the extended absorption peaks at 1516 and $1379 \mathrm{~cm}^{-1}$ among the treatments indicating those peaks are indicative only for the mycoparasite treatment as potential signatory molecules.

The peak at $1250-1246 \mathrm{~cm}^{-1}$ (C-O stretching) was mainly assigned as hemicellulose [24] and might be supported partly by asymmetric $\mathrm{P}=\mathrm{O}$ stretching (of $\mathrm{PO}^{2-}$ ) for phospholipids and nucleic acids. Mycoparasite treatment showed an increase in the intensity of the peak compared with the control and Fusarium treatment, which implies a more presence of hemicellulose, phospholipids, and nucleic acids. The tendency for the increased hemicellulose during the interaction with plant pathogens was reported for the susceptible and resistant plants (canola roots) related to plant resistance responses [24]. Therefore, it was assumed that hemicelluloses with some potential compounds other than lignins are considerably involved in plant resistance derived by the mycoparasite in our study.

Besides those prominent peaks, the second prominent peak was observed at 1058-1036 $\mathrm{cm}^{-1}$ attributable to $\mathrm{C}-\mathrm{O}-\mathrm{C}$ symmetrical stretching, C-C, C-O stretching or $\mathrm{C}-\mathrm{OH}$ bending of primary and secondary alcohols such as carbohydrates (mainly cellulose, hemicellulose). The extended region between $1200-900 \mathrm{~cm}^{-1}$ may indicate very complex contributions from different cell wall components (cellulose and hemicellulose) such as arabinoxylans (especially, main hemicellulose in wheat and barley) and xyloglucan (generally known as abundant hemicellulose in all plants) for which, the peak at $1157-1153 \mathrm{~cm}^{-1}$ may be responsible for mainly $\mathrm{C}-\mathrm{O}-\mathrm{C}$ asymmetric stretching and $\mathrm{C}-\mathrm{O}$ stretching, as well as, cellular components such as phospholipids and nucleic acids which may be partly supported by the peak at $1077-1076 \mathrm{~cm}^{-1}$ along with $1250-1246 \mathrm{~cm}^{-1}$ attributable to symmetric and asymmetric stretching of $\mathrm{P}=\mathrm{O}$ stretching $\left(\mathrm{PO}^{2-}\right)$, respectively. In this region, MFR showed a relatively reduced intensity of the peak compared with FR and SR, implying that mycoparasite treatment possesses less cellulose.

\subsubsection{Principal Component Analysis (PCA)}

The principal component analysis (PCA) was performed to classify the data (FTIR spectra) among the treatments.

The two-dimensional score plot of the PCA in Figure 4 indicated the clear separations among the root samples between the treatments with the fungi and the control. The PC1 and 
the PC2 explained $80.7 \%$ of the total spectral variance. The PC1 axis clearly distinguished MFR as a separate cluster on the positive side of PC1 from FR on the negative side of PC1, which indicates the significant difference of biochemical components depending on the presence of mycoparasite and the effect of mycoparasitism. The control (SR) showed the tendency to spread along the PC1 axis with a tilt to the positive side of PC2. The PC2 axis allowed the separation of SR clustered on the positive side of PC2, from FR clustered on the negative side of PC2. The MFR was scattered near the PC2 axis.

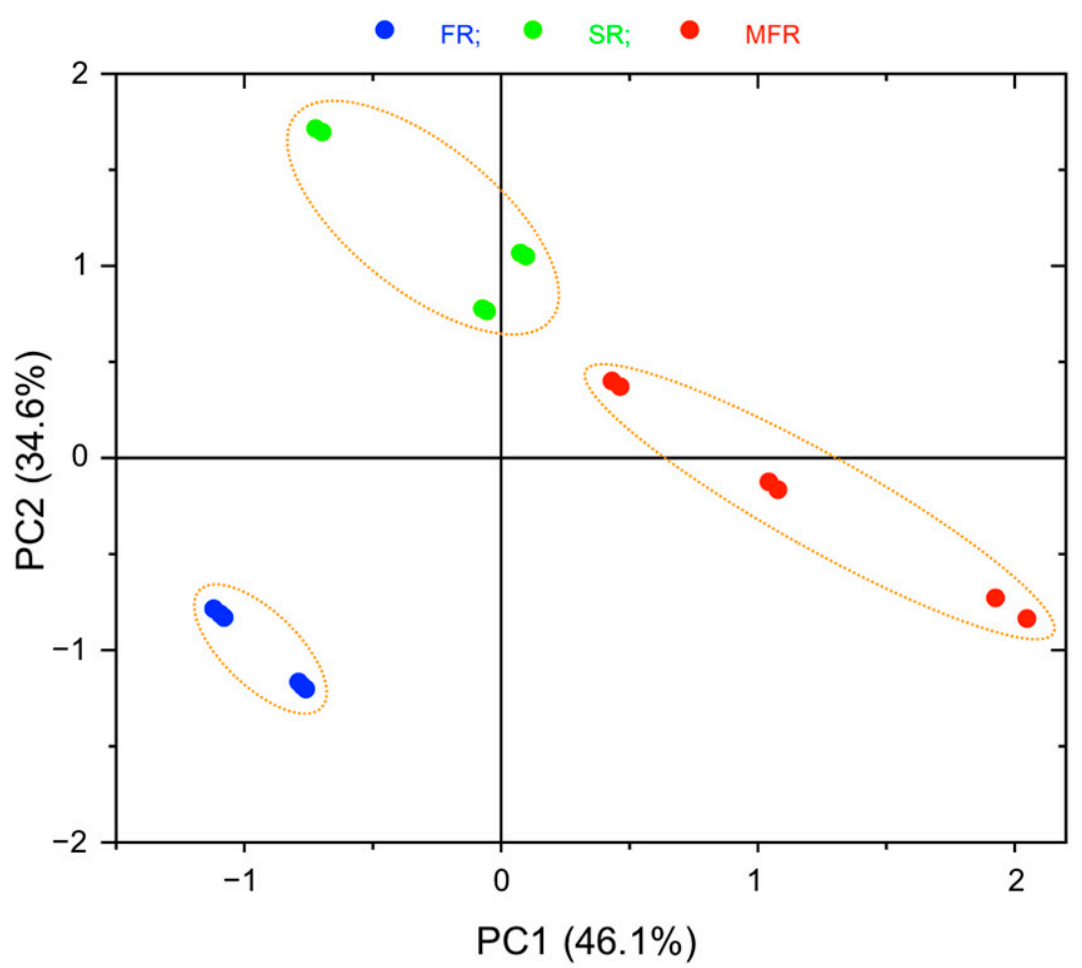

Figure 4. The scatter score plot based on principal component analysis of the FTIR spectra of the root samples. Each of the roots ( $n=3$; each pellet was measured two times) was collected from the seed surrounded by S. mycoparasitica against F. graminearum (MFR, red dot); the seed infected by F. graminearum (FR, blue dot); the non-treated or non-infected seed (SR, green dot).

The loadings plot of PC1 and PC2 are shown in Figure 5. In the region between 4000$3200 \mathrm{~cm}^{-1}$, the negative influence of PC1 loadings had one peak at $3445 \mathrm{~cm}^{-1}$, whereas the positive influence of $\mathrm{PC} 1$ had no peak. For PC2 loadings, the positive influence and negative influence were observed at 3403 and $3603 \mathrm{~cm}^{-1}$, respectively. These peaks may be partly supportive to differentiate roots (samples) due to the variations of possible molecules including carbohydrates, glycoconjugates, and proteins.

For the lipid region between $3050-2800 \mathrm{~cm}^{-1}$, the three peaks at $2959 \mathrm{~cm}^{-1}$ (asymmetric $\mathrm{CH}_{3}$ stretching), $2928 \mathrm{~cm}^{-1}$ (asymmetric $\mathrm{CH}_{2}$ stretching), and $2855 \mathrm{~cm}^{-1}$ (symmetric $\mathrm{CH}_{2}$ stretching) on the positive influence of $\mathrm{PC} 1$ loadings are supportive to distinguish MFR from FR. Further, the negative influence of PC2 loadings shown at $2926 \mathrm{~cm}^{-1}$ (asymmetric $\mathrm{CH}_{2}$ stretching) and $2854 \mathrm{~cm}^{-1}$ (symmetric $\mathrm{CH}_{2}$ stretching) clearly differentiated FR from SR. Therefore, the increase in the lipid region of FR and MFR may imply that biotic factors such as F. graminearum and S. mycoparasitica (more prominent) contribute to the content of lipids on roots directly or indirectly.

For the region between $1800-800 \mathrm{~cm}^{-1}$, the positive influence of PC1 loadings had peaks at $1746,1655,1547$, and $1240 \mathrm{~cm}^{-1}$ which were assigned to carbonyl compounds (partly pectin), protein amide I ( $\alpha$-helices), amide II, and (mostly) hemicellulose, respectively, which were supportive to indicate these possible components were much more dominant in MFR (the mycoparasite treated Fusarium samples) than FR, of which, variation 
of protein composition was mainly responsible for the differentiation, significantly. The negative influence of PC1 loadings was shown at $1019 \mathrm{~cm}^{-1}$.

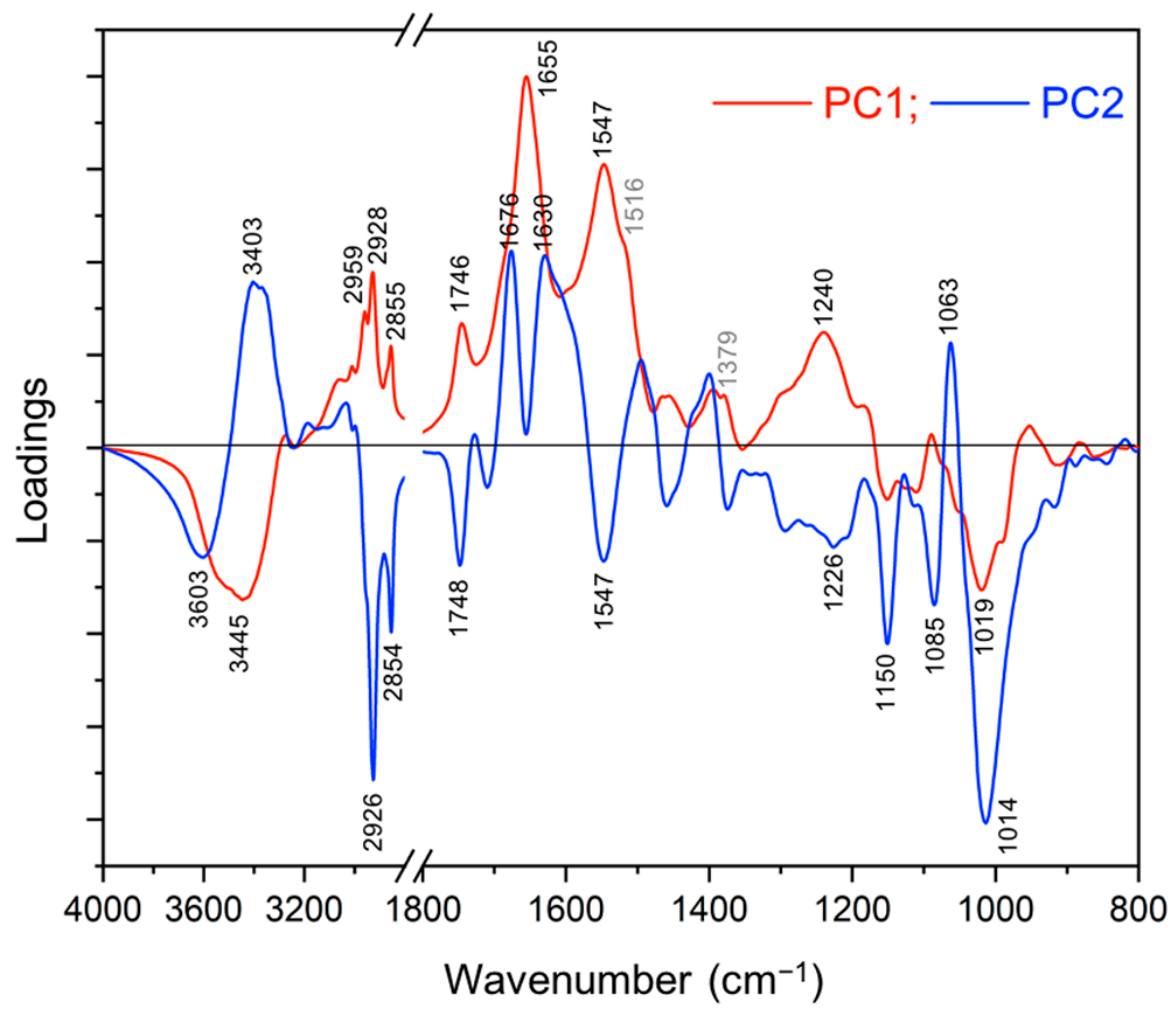

Figure 5. Loadings plot (PC1 \& PC2) of the root samples based on the FTIR spectra. Each point in the plot represents the projection of a spectrum in the PC1-PC2 space.

The positive influence of PC2 loadings had three peaks at $1676,1630 \mathrm{~cm}^{-1}$ assigned to amide I ( $\beta$-turns and $\beta$-sheets), and $1063 \mathrm{~cm}^{-1}$ (mostly might be related to cellulose and hemicellulose) which differentiated the control SR (outstanding) from the FR. The negative influence of PC2 loadings showed the peaks at 1748, 1547, 1226, 1150, 1085, and $1014 \mathrm{~cm}^{-1}$ which also contributed to the differentiation of FR from SR by the tentative assignments of $1748 \mathrm{~cm}^{-1}$ to carbonyl compounds; $1547 \mathrm{~cm}^{-1}$ to amide II; $1226,1014 \mathrm{~cm}^{-1}$ to carbohydrate; $1150,1085 \mathrm{~cm}^{-1}$ to phospholipids and nucleic acids.

In regard to the peak at $1516 \mathrm{~cm}^{-1}$, which has been previously assigned to lignin according to Lahlali et al. [24], this peak at the near region $\left(1520-1500 \mathrm{~cm}^{-1}\right)$ could be derived from any other aromatic or phenolic compounds due to $\mathrm{C}=\mathrm{C}$ stretching of aromatic rings, with contributions at $1379 \mathrm{~cm}^{-1}$ which may be due to overlapping $\mathrm{C}-\mathrm{OH}$ deformation of phenols and $\mathrm{CH}$ bending in aromatics [44-46].

Taken together, those noticeable peaks (at 1746, 1655, 1547, $1240 \mathrm{~cm}^{-1}$ ) along with other detectable peaks $\left(1516,1379 \mathrm{~cm}^{-1}\right)$ imply existence of important signatory molecules defining mycoparasitism within this tripartite interactome profile, which could be a good example to investigate the mycoparasite effects on Fusarium in the presence of plant.

\subsubsection{Estimation of Protein Secondary Structures in Tripartite System}

The contributions of the protein secondary structures to the cell membrane are recognized as stress resilience factors in plants [21,47]. The protein secondary structural profiles of the germinating seed roots were estimated for each of the three biological (SR, FR, and MFR) samples. Figure 6 shows curve fitting results to $\alpha$-helices, $\beta$-sheets, coils, and random. The fraction of each protein secondary structure associated with each of the biological treatments is listed in Table 3. Results indicate interesting differences in $\alpha$-helical and $\beta$-sheets structures between biological treatments. The FTIR results depicted SR control 
with a relatively large amount $(50.7 \%)$ of $\alpha$-helices $\left(1650-1658 \mathrm{~cm}^{-1}\right)$. In germinating seed, primary root interaction with fungi decreased $\alpha$-helices in host cells, which was less pronounced in MFR (4.2\%) mycoparasite-Fusarium compared to FR pathogen (3.0\%) samples. It is known that the $\alpha$-helical structure proteins are particularly abundant in the cell membrane [47]. The $\beta$-sheets, consisted of $\beta$-sheet I (at $1630-1642 \mathrm{~cm}^{-1}$ ) and $\beta$-sheet II for turns and loops structures (at 1694-1682 $\mathrm{cm}^{-1}$ ), showed an inverse relationship with decreasing values from FR $61.2 \%$ to MRF $53.1 \%$ followed by SR $45.6 \%$. The ratio between the $\alpha$-helices: $\beta$-sheets parameter indicates the highest stress induced by FR $(0.05)$ compared to MFR (0.08) which is a more adaptive endophytic interaction that protects germinating seed during mycoparasitism compared to aggressive-disease causing Fusarium plant pathogen [14].
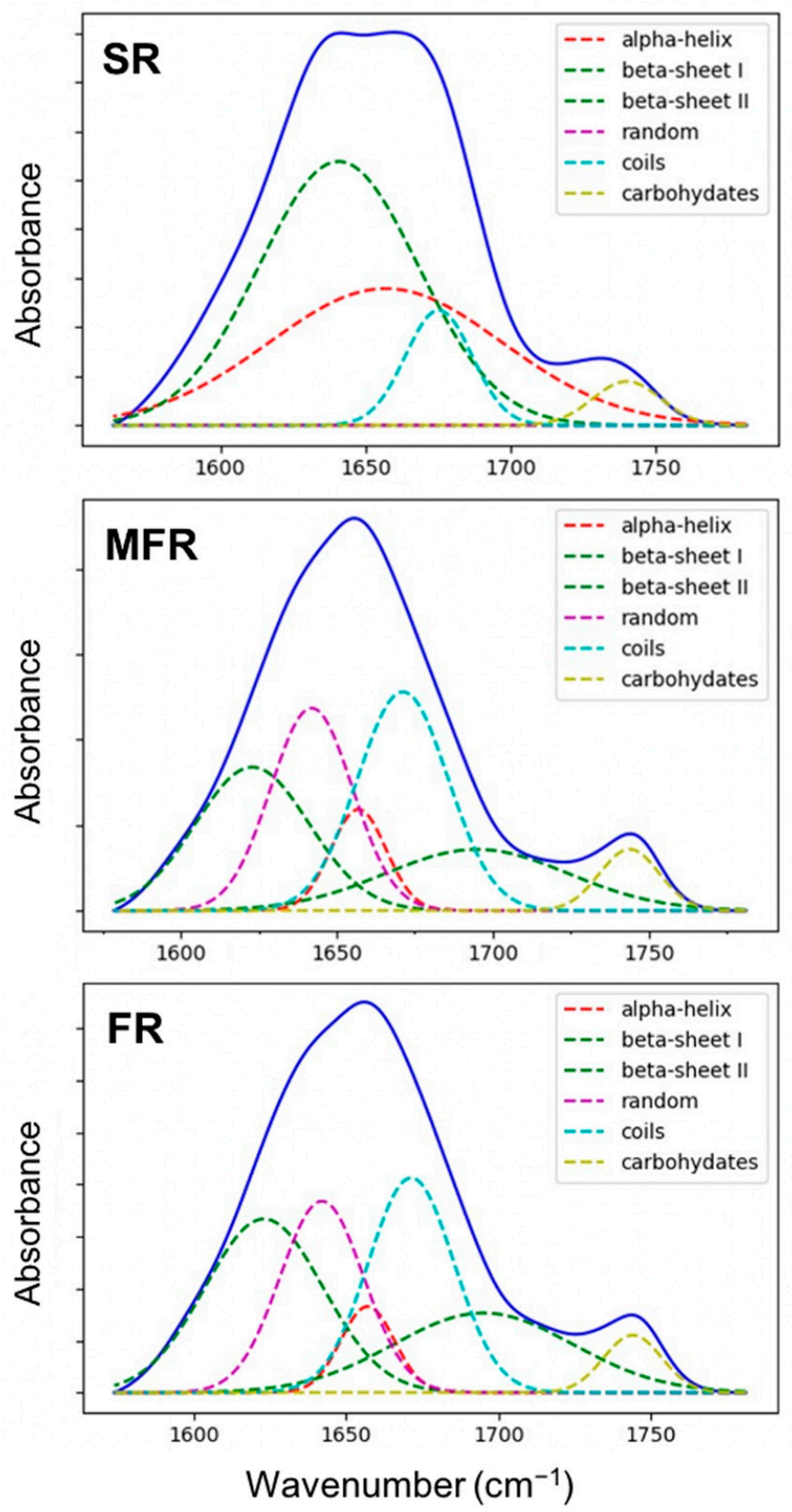

Figure 6. Curve fitting of the region (1580-1780 $\left.\mathrm{cm}^{-1}\right)$ for the root samples derived from each treatment (SR, the non-treated seed; MFR, the seeds surrounded by S. mycoparasitica against F. graminearum; FR, the seed infected by F. graminearum). Each spectrum is the average of 6 spectra. 
Table 3. Secondary protein structures (expressed as \%) of the root samples derived from each treatment (SR, the non-treated seed; MFR, the seeds surrounded by S. mycoparasitica against F. graminearum; FR, the seed infected by F. graminearum).

\begin{tabular}{cccccc}
\hline Protein & \multicolumn{3}{c}{ Treatment } & \multicolumn{2}{c}{ Ratio } \\
\cline { 2 - 6 } Structure & SR & MFR & FR & SR:MFR & SR:FR \\
\hline$\alpha$-helices & 50.7 & 4.2 & 3.0 & 12.07 & 16.9 \\
$\beta$-sheets (I + II) & 45.6 & 53.1 & 61.2 & 0.86 & 0.75 \\
Coils & 3.5 & 24.3 & 19.4 & 0.14 & 0.18 \\
Random & 0.2 & 18.4 & 16.4 & 0.01 & 0.02 \\
\hline
\end{tabular}

Data were estimated from the average of 6 spectra per treatment. The percentage indicates a certain proportion of each protein structure to the total protein structures $(100 \%)$.

Interestingly, the increased content of the $\alpha$-helix band over $\beta$-sheet may suggest a higher sugar-protein presence in the matrix of MFR sample, such as trehalose $\left(1657 \mathrm{~cm}^{-1}\right)$, which may act as stabilizing stress compound. It could be produced by Sphaerodes mycoparasitica interacting with Fusarium pathogen in MFR, as the trehalose seemed to enhance the efficacy of the biocontrol agent against pathogenic molds [48]. According to FTIR study conducted by Imamura et al. [49], the trehalose embedded into protein matrix can also improve the cell membrane stability as measured by increased $\alpha$-helix content $(19 \% \rightarrow 45 \%)$, which was inversely correlated to $\beta$-sheet content $(8 \% \rightarrow 4 \%)$, that aligned with results of this study.

Lahlali et al. [21] have also found, in the pea pollen grain system, that the protein richness with $\alpha$-helical structures is positively correlated with the protective effects on dehydration due to heat stress. Using FTIR spectroscopy, Belton et al. [50] study also proposed that the trehalose sugar molecules can markedly increase hydrogen-bonding contributions to the protein stability, which helps organisms exposed to stress in retaining cellular integrity. This effect is maximized when the water molecules are entrapped at the interface between the protein and the amorphous sugar matrix [50]. It seems that both water replacement and water entrapment are possible mechanisms mediated by hydrogen bonding, which occurs between the sugar and the protein [51].

Other secondary structural contributions such as coils and random protein structures were observed more in MFR and FR than in the control samples. It seems that under stressed conditions, there is a disordered protein structure with an increase in random and coils fraction, likely due to the more production of compatible solutes (sugars) in order to alleviate water stress [52]. This phenomenon was more pronounced in MFR treatment (42.7\%) than in FR treatment (35.8\%); suggesting that the endophyte fungus is contributing more to membrane integrity and stability under stress. However, the significance of those results is unclear, while no corresponding results were published for three-partite biological system interaction.

The carbonyl secondary structures $\left(1760-1710 \mathrm{~cm}^{-1}\right)$ usually provide information about the polar interfacial regions of membrane lipids or pectin $[26,53]$ related to the biological membrane activity and structural flexibility. A shift in the absorption peaks in the carbonyl ester region was observed between MFR and FR indicating changes in the lipids, pectin compositions, or other carbonyl compounds between the two samples and relatively more stress induced by FR-Fusarium alone on germinating seed radicle compared to MFR (mycoparasite + Fusarium) and non-treated SR samples. The results in this study based on the biological stress response in wheat corroborate with abiotic stress response in other agricultural crops such as pea pollen [21], which merits further investigation.

Overall, it seems that modification of the protein secondary structure (PSS) based on $\alpha$-helices: $\beta$-sheets fraction could be directly or indirectly related to the resistance of wheat tissue samples to combined biotic (plant pathogen) and abiotic (dehydration) stress. However, whether or not the PSS control dehydration during the host cell-fungus interaction or the sugar-trehalose embedded into protein matrix to improve cell membrane stability as a strategy to counter pathogen need to be further explored. 
Overall, the tripartite [mycoparasite-Fusarium-germinating seed] interaction results in the formation of a "triangular" S. mycoparasitica-F. graminearum hyphal network in which the infectious mycoparasitic hooked cells invade Fusarium hyphae for better control of Fusarium that coincides with a considerable shift in the protective host plant signatory molecules.

\section{Materials and Methods}

\subsection{Plant and Fungal Materials}

The present study was carried out using surface-sterilized seeds of AC Avonlea wheat (Triticum turgidum L. ssp. durum (Desf)) - grown in a controlled CONVIRON ${ }^{\circledR}$ PGR15 growth chamber (Controlled Environments Ltd., Winnipeg, MB, Canada) at the University of Saskatchewan and the surface-sterilized seeds were certified to be free of microbes [15]. The wheat seeds were surface-sterilized with the following steps as previously described [54,55]: immersing them in 95\% ethanol for $10 \mathrm{~s}$, rinsing in sterile distilled water for $10 \mathrm{~s}$, submerging for $1 \mathrm{~min}$ in $5 \%$ sodium hypochlorite, and then rinsing three times in sterile distilled water. The Avonlea-durum variety was selected due to its low resistance to environmental stresses including FHB causing pathogens [56]. For this study, two fungal isolates from the Saskatchewan Microbial Collection and Database (SMCD), biocontrol SMCD 2220-01 strain of S. mycoparasitica Vujan. (2009) as a Fusarium specific mycoparasite [57,58], and SMCD 2243 F. graminearum Schwabe 3-ADON chemotype as a virulent plant pathogenic strain $[13,59]$ were used. The fungi were grown on Potato Dextrose Agar (PDA) medium at $23^{\circ} \mathrm{C}$ in darkness for 7 days and fresh cultures were used for in vitro assay.

\subsection{In Vitro Wheat Seed Germination Assay}

In vitro wheat seed germination and early stage growth of germinating seeds were examined in the Biosafety-2 level lab at the University of Saskatchewan. The assessment was performed under the digital stereo microscope (DSM, Fisherbrand ${ }^{\mathrm{TM}}$ DC5420THFisher Scientific, Ottawa, ON, Canada) (Figure 1A-F) microscope to investigate the effects of the mycoparasite $S$. mycoparasitica on the seed germination and changes in biochemical components of the wheat roots (radicles and seminar roots) against the plant pathogenic F. graminearum 3-ADON. The first treatment was composed of an agar plug $\left(8 \mathrm{~mm}^{2}\right)$ of S. mycoparasitica pre-inoculated on a PDA plate. After 2-day incubation of S. mycoparasitica, the pre-inoculated plug was gently removed from the plate to remain the mycelium of S. mycoparasitica on the plate. Then, a surface-sterilized seed of AC Avonlea was inoculated onto the mycelium of $S$. mycoparasitica. After 1-day incubation of the seed, an agar plug of F. graminearum was inoculated on the plate. The distance between F. graminearum and the seed surrounded by the mycelium of the mycoparasite (S. mycoparasite) was $0.5 \mathrm{~cm}$ (seed with $S$. mycoparasite against F. graminearum). The second treatment consisted only of the applied F. graminearum. A surface-sterilized seed was inoculated on a PDA plate. After 1-day incubation of the seed, an agar plug of F. graminearum was placed on the plate keeping the distance $0.5 \mathrm{~cm}$ away from the seed (seed against F. graminearum). As a non-treatment, a surface-sterilized seed was inoculated on a PDA plate (seed only). All the plates (9 cm diameter Petri dishes) were sealed with two layers of parafilm to maintain water activity $\left(a_{w}=0.97\right)$ and kept at $23{ }^{\circ} \mathrm{C}$ in darkness during the incubation period. Each treatment includes 10 replicates. The 1 and 2-day-old seeds were counted for germination through direct or macroscopic observation. To obtain better quality of images, samples were transferred onto new Petri dishes and images were taken under the DSM. Percentage of seed germination (\%) was calculated (Figure 2) with the following formula: (number of germinated seeds in particular treatment/number of germinated seeds in control) $\times 100$; here, the control refers to the non-treated seed at day 2 [14]. For statistical analysis, three sets of germination (\%) data were analyzed by one-way analysis of variance (ANOVA) with Tukey's honestly significant difference (HSD) test $(p<0.05)$. The seed, radicle, and seminal root were then subjected to the sampling, microscopy, and FTIR spectroscopy analyses. 


\subsection{Scanning Electron and Confocal Laser Scanning Microscopy}

In order to observe the mycoparasitism on Fusarium host (Figure 1G-I), Scanning Electron Microscopy (SEM) and Confocal Laser Scanning Microscopy (CLSM) were applied by using an Ultra-High Resolution $(1.0 \mathrm{~nm}$ ) Scanning Electron Microscope (Hitachi SU8010 FE-SEM) operating at 3kV and Confocal Laser Scanning Microscope (Leica TCS-SP5) equipped with Leica LAS AF imaging software at the University of Saskatchewan-WCVM Imaging Centre. For the SEM sample preparation, the interaction zone of the mycoparasite and Fusarium host on the agar (approximately $0.5 \mathrm{~cm}^{2}$ ) was dissected and subjected to protocols [60] with slight modifications. The excised blocks of agar with the mycelia or interacting hyphae were pre-fixed in $2 \%$ glutaraldehyde (GA) in $0.1 \mathrm{M}$ sodium cacodylate $(\mathrm{NaCAC})$ at $\mathrm{pH} 7.2$ for $1 \mathrm{~h}$ then rinsed with $0.1 \mathrm{M} \mathrm{NaCAC}$ and stored at $4{ }^{\circ} \mathrm{C}$ prior to the osmium fixation. The pre-fixed samples were fixed with $1 \%$ osmium tetraoxide $\left(\mathrm{OsO}_{4}\right)$ in $0.1 \mathrm{M} \mathrm{NaCAC}$ for $1 \mathrm{hr}$ then, rinsed with sterile distilled water three times. Subsequently, the fixed samples were proceeded to following procedures; gradual dehydration with ethanol, substitution with amyl acetate, critical point drying on Polaron E3000, and coating with gold (10 nm thickness) using Q150T ES Quorum, turbo-pumped sputter coater [15]. For the CLSM, the mycoparasite and Fusarium host were co-cultured directly on a sterilized slide glass by providing $100 \mu \mathrm{L}$ of potato dextrose broth for 2.5 days and then stained with $50 \mu \mathrm{L}$ of $0.01 \%$ Lacto-fuchsin prior to the observation. The CLSM image was generated by using the open-source platform Fiji for biological-image analysis [61].

\subsection{Preparation of the Root Samples for FTIR Spectroscopy}

Germinating seed samples consisted of the radicle (primary root) and seminar roots collected by sterile blades under the DMS, gently washed with sterile distilled water, and lyophilized for 2 days to remove any residual moisture prior to sample preparation for FTIR spectroscopy (Canadian Light Source) using Bruker IFS 66V/S spectrometer) (Bruker Optics, Ettlingen, Germany) equipped with a KBr beam splitter at the mid-infrared beam. The freeze-dried pooled samples for each sample type were ground up to fine powders by using a mortar and a pestle to make the samples homogenous. The fine powder was ground (3 replicates for each sample type) with potassium bromide $(\mathrm{KBr})$ to prepare pellets at the concentration of the sample in $\mathrm{KBr}$ of $1.3 \%$. The prepared powders were pressurized under 55.16 Kilopascals $(\mathrm{kPa})$ for 2 min to make transparent pellets ( $12 \mathrm{~mm}$ diameter) and kept in a desiccator until FTIR measurement [18]. The FTIR measurement was performed twice for each sample type. The Bruker IFS 66V/S spectrometer (Bruker Optics, Ettlingen, Germany) equipped with a $\mathrm{KBr}$ beam splitter at the mid-infrared beamline using the globar (silicon carbide) as the infrared source was used to collect FTIR spectra. Each IR spectrum was measured and recorded in the range of $4000-600 \mathrm{~cm}^{-1}$ at the resolution of $2 \mathrm{~cm}^{-1}$ and 64 scans per sample [24]. The number of replicates was 3 for each sample type. A KBr pellet without a sample was used as a blank for the background measurement.

\subsection{FTIR Data Analysis}

FTIR data analysis and plotting were accomplished using OPUS (version 7.2, Bruker Optik GmbH, Bruker Optics Inc., Billerica, MA, USA) and Origin Pro (version 9.1, OriginLab Corporation, Northampton, MA, USA) programs. First, the pure $\mathrm{KBr}$ spectra were used to normalize FTIR spectra of the samples. The normalized FTIR spectra were baseline corrected using the rubber band correction (64 points), vector normalized, and averaged using the OPUS software (Figure 3). The FTIR peaks (Table 1) were determined using the Quick Peaks routine in Origin Pro with the settings of local maximum at $0 \%$ threshold height, no baseline, and area at $Y=0$ [18]. The individual FTIR spectrum was integrated by the Peak Analyzer in Origin Pro with the settings of local maximum at 20\% threshold height and $Y=0$. The obtained (absorption) peak areas were analyzed by one-way ANOVA $(p<0.05)$ with Tukey's HSD test (Table 2). The tentative assignment of the peaks representing different functional groups of compounds was performed in comparison with Web of Science published data and a largely accepted list of references [24-35], dataset, and 
information. The baseline corrected and vector normalized spectra were used for principal component analysis (PCA) to differentiate treatments and the scatter score and loading plots were shown in Figures 4 and 5, respectively.

\subsection{Protein Secondary Structure Analysis}

Once the spectral averages were calculated for each of the samples, the data was cropped between 1520 and $1780 \mathrm{~cm}^{-1}$ for further processing. A linear baseline was subtracted from the spectra before being fit to a 6 component Gaussian non-linear curve fitting model utilizing the Python package-Non-Linear Least-Squares Minimization and CurveFitting for Python, available online: https:/ / lmfit.github.io/lmfit-py / (Available online 5 December 2020). The peak areas of each component were calculated from the resulting parameter fits to yield percentage estimates of the various secondary structure motifs. This procedure was implemented using Quasar (Orange Spectroscopy [62]). The area under the entire band was considered $100 \%$ and each component after fitting was expressed as a percent fraction [21].

\section{Conclusions}

The wheat seed germination rate (\%) was improved when the seed was protected by S. mycoparasitica against virulent $F$. graminearum 3-ADON chemotype. This implies that an early preventive biocontrol measure is possible to suppress the establishment of FHB pathogens in cereal crops. Further, the FTIR spectra showed biochemical changes in the root cells of the seed germinants under the tripartite S. mycoparasitica-F. graminearum-plant host interaction. Although the fungal treatment was associated with considerable shifts in the FTIR spectra, it is probable that the protective S. mycoparasitica induced multiple signatory molecules defining mycoparasitism. This finding indicates that $S$. mycoparasitica plays a crucial role in promoting wheat fitness by increasing defense responses of the germinating seed (root) against early F. graminearum colonization of the plant host. The spectral peaks related to mycoparasitism were noticeable mainly within the region of proteins and lipids, also indicating a link between carbohydrates and protein regions, involving potential phenolic compounds. A modification of the protein secondary structure, based on $\alpha$-helices: $\beta$-sheets fraction, may further contribute to wheat cell membrane stability. Therefore, the effect of $S$. mycoparasitica on the wheat seed at a molecular level merits further examination to investigate bioactive compounds in providing prenatal care to plants against $F$. graminearum via endophytic mycoparasitism.

Author Contributions: Conceptualization, S.H.K. and V.V.; methodology, S.H.K. and V.V. (FTIR section, R.L. and C.K.); formal analysis, S.H.K. and V.V. (FTIR analysis, R.L. and C.K.); investigation, S.H.K. and V.V.; resources, V.V.; writing—original draft preparation, S.H.K. and V.V.; writing-review and editing, S.H.K., V.V., R.L. and C.K.; visualization, S.H.K. and V.V.; supervision, V.V.; project administration, V.V.; funding acquisition, V.V. All authors have read and agreed to the published version of the manuscript.

Funding: This research was funded by the Natural Sciences and Engineering Research Council of Canada (NSERC) Discovery grant (RGPIN-2017-05286) and Government of SaskatchewanAgriculture Development Fund (ID: 20160226) and Saskatchewan Wheat Development Commission (ID: 171025-65) external funding to V. Vujanovic. Part of the research presented here was performed at the Canadian Light Source, which is supported by the CFI, NSERC, NRC, CIHR, Government of Saskatchewan, and the University of Saskatchewan.

Institutional Review Board Statement: Not applicable.

Informed Consent Statement: Not applicable.

Data Availability Statement: Not applicable.

Acknowledgments: We would like to thank Eiko Kawamura and Scott Rosendahl for their valuable assistance.

Conflicts of Interest: The authors declare no conflict of interest. 


\section{References}

1. Vujanovic, V.; Islam, M.N.; Daida, P. Transgenerational role of seed mycobiome-An endosymbiotic fungal composition as a prerequisite to stress resilience and adaptive phenotypes in Triticum. Sci. Rep. 2019, 9, 18483. [CrossRef]

2. Bruinsma, J. World Agriculture: Towards 2015/2030 Summary Report; Food and Agriculture Organization of the United Nations (FAO): Rome, Italy, 2002.

3. Vujanovic, V.; Germida, J.J. Seed endosymbiosis: A vital relationship in providing prenatal care to plants. Can. J. Plant Pathol. 2017, 97, 972-981. [CrossRef]

4. Osborne, L.E.; Stein, J.M. Epidemiology of Fusarium head blight on small-grain cereals. Int. J. Food Microbiol. 2007, 119, 103-108. [CrossRef] [PubMed]

5. Schöneberg, A.; Musa, T.; Voegele, R.T.; Vogelgsang, S. The potential of antagonistic fungi for control of Fusarium graminearum and Fusarium crookwellense varies depending on the experimental approach. J. Appl. Microbiol. 2015, 118, 1165-1179. [CrossRef]

6. Karlsson, M.; Durling, M.B.; Choi, J.; Kosawang, C.; Lackner, G.; Tzelepis, G.D.; Nygren, K.; Dubey, M.K.; Kamou, N.; Levasseur, A.; et al. Insights on the evolution of mycoparasitism from the genome of Clonostachys rosea. Genome Biol. Evol. 2015, 7, 465-480. [CrossRef]

7. Vieira, P.M.; Coelho, A.S.; Steindorff, A.S.; de Siqueira, S.J.; Silva Rdo, N.; Ulhoa, C.J. Identification of differentially expressed genes from Trichoderma harzianum during growth on cell wall of Fusarium solani as a tool for biotechnological application. BMC Genomics 2013, 14, 177. [CrossRef] [PubMed]

8. $\quad$ Nygren, K.; Dubey, M.; Zapparata, A.; Iqbal, M.; Tzelepis, G.D.; Durling, M.B.; Jensen, D.F.; Karlsson, M. The mycoparasitic fungus Clonostachys rosea responds with both common and specific gene expression during interspecific interactions with fungal prey. Evol. Appl. 2018, 11, 931-949. [CrossRef]

9. Kim, S.H.; Vujanovic, V. Biodegradation and biodetoxification of Fusarium mycotoxins by Sphaerodes mycoparasitica. AMB Express 2017, 7, 145. [CrossRef]

10. Vujanovic, V.; Korber, D.R.; Vujanovic, S.; Vujanovic, J.; Jabaji, S. Scientific prospects for cannabis-microbiome research to ensure quality and safety of products. Microorganisms 2020, 8, 290. [CrossRef]

11. Pal, K.K.; Gardener, B.M. Biological control of plant pathogens. Plant Health Instr. 2006, 2, 1117-1142. [CrossRef]

12. Kim, S.H.; Vujanovic, V. Relationship between mycoparasites lifestyles and biocontrol behaviors against Fusarium spp. and mycotoxins production. Appl. Microbiol. Biotechnol. 2016, 100, 5257-5272. [CrossRef]

13. Vujanovic, V.; Kim, S.H. Adaptability of mitosporic stage in Sphaerodes mycoparasitica towards its mycoparasitic-polyphagous lifestyle. Mycologia 2017, 109, 701-709. [CrossRef]

14. Vujanovic, V.; Goh, Y.K. qPCR quantification of Sphaerodes mycoparasitica biotrophic mycoparasite interaction with Fusarium graminearum: In vitro and in planta assays. Arch. Microbiol. 2012. [CrossRef] [PubMed]

15. Vujanovic, V.; Kim, S.H.; Lahlali, R.; Karunakaran, C. Spectroscopy and SEM imaging reveal endosymbiont-dependent components changes in germinating kernel through direct and indirect coleorhiza-fungus interactions under stress. Sci. Rep. 2019, 9, 1665. [CrossRef]

16. Ding, L.; Xu, H.; Yi, H.; Yang, L.; Kong, Z.; Zhang, L.; Xue, S.; Jia, H.; Ma, Z. Resistance to hemi-biotrophic F. graminearum infection is associated with coordinated and ordered expression of diverse defense signaling pathways. PLoS ONE 2011, 6, e19008. [CrossRef] [PubMed]

17. Gauthier, L.; Atanasova-Penichon, V.; Chéreau, S.; Richard-Forget, F. Metabolomics to decipher the chemical defense of cereals against Fusarium graminearum and deoxynivalenol accumulation. Int. J. Mol. Sci. 2015, 16, 24839-24872. [CrossRef]

18. Lahlali, R.; Karunakaran, C.; Wang, L.; Willick, I.; Schmidt, M.; Liu, X.; Borondics, F.; Forseille, L.; Fobert, P.R.; Tanino, K.; et al. Synchrotron based phase contrast X-ray imaging combined with FTIR spectroscopy reveals structural and biomolecular differences in spikelets play a significant role in resistance to Fusarium in wheat. BMC Plant Biol. 2015, 15, 24. [CrossRef]

19. Wachowska, U.; Tańska, M.; Konopka, I. Variations in grain lipophilic phytochemicals, proteins and resistance to Fusarium spp. growth during grain storage as affected by biological plant protection with Aureobasidium pullulans (de Bary). Int. J. Food Microbiol. 2016, 227, 34-40. [CrossRef] [PubMed]

20. Zimmermann, B.; Kohler, A. Infrared spectroscopy of pollen identifies plant species and genus as well as environmental conditions. PLoS ONE 2014, 9, e95417. [CrossRef] [PubMed]

21. Lahlali, R.; Jiang, Y.; Kumar, S.; Karunakaran, C.; Liu, X.; Borondics, F.; Hallin, E.; Bueckert, R. ATR-FTIR spectroscopy reveals involvement of lipids and proteins of intact pea pollen grains to heat stress tolerance. Front. Plant Sci. 2014, 5. [CrossRef]

22. Jiang, Y.; Lahlali, R.; Karunakaran, C.; Kumar, S.; Davis, A.R.; Bueckert, R.A. Seed set, pollen morphology and pollen surface composition response to heat stress in field pea. Plant Cell Environ. 2015. [CrossRef]

23. Lahlali, R.; Song, T.; Chu, M.; Karunakaran, C.; Yu, F.; Wei, Y.; Peng, G. Synchrotron-based spectroscopy and imaging reveal changes in the cell-wall composition of barley leaves in defence responses to Blumeria graminis f. sp. tritici. Can. J. Plant Pathol. 2019, 41, 457-467. [CrossRef]

24. Lahlali, R.; Song, T.; Chu, M.; Yu, F.; Kumar, S.; Karunakaran, C.; Peng, G. Evaluating changes in cell-wall components associated with clubroot resistance using Fourier Transform Infrared Spectroscopy and RT-PCR. Int. J. Mol. Sci. 2017, 18, 2058. [CrossRef]

25. Hardoim, P.R.; Guerra, R.; Costa, A.M.R.D.; Serrano, M.S.; Sánchez, M.E.; Coelho, A.C.; Stenlid, J. Temporal metabolic profiling of the Quercus suber-Phytophthora cinnamomi system by middle-infrared spectroscopy. For. Pathol. 2016, 46, 122-133. [CrossRef] 
26. Thumanu, K.; Sompong, M.; Phansak, P.; Nontapot, K.; Buensanteai, N. Use of infrared microspectroscopy to determine leaf biochemical composition of cassava in response to Bacillus subtilis CaSUT007. J. Plant Interact. 2015, 10, 270-279. [CrossRef]

27. Lahlali, R.; Kumar, S.; Wang, L.; Forseille, L.; Sylvain, N.; Korbas, M.; Muir, D.; Swerhone, G.; Lawrence, J.R.; Fobert, P.R.; et al. Cell wall biomolecular composition plays a potential role in the host type II resistance to Fusarium Head Blight in wheat. Front. Microbiol. 2016, 7, 910. [CrossRef]

28. Kačuráková, M.; Wellner, N.; Ebringerová, A.; Hromádková, Z.; Wilson, R.H.; Belton, P.S. Characterisation of xylan-type polysaccharides and associated cell wall components by FT-IR and FT-Raman spectroscopies. Food Hydrocoll. 1999, $13,35-41$. [CrossRef]

29. Lasch, P.; Naumann, D. Infrared Spectroscopy in Microbiology. In Encyclopedia of Analytical Chemistry; John Wiley \& Sons: Hoboken, NJ, USA, 2015; pp. 1-32. [CrossRef]

30. Perez-Guaita, D.; Kochan, K.; Martin, M.; Andrew, D.W.; Heraud, P.; Richards, J.S.; Wood, B.R. Multimodal vibrational imaging of cells. Vib. Spectrosc. 2017, 91, 46-58. [CrossRef]

31. Durak, T.; Depciuch, J. Effect of plant sample preparation and measuring methods on ATR-FTIR spectra results. Environ. Exp. Bot. 2020, 169, 103915. [CrossRef]

32. Mallamace, F.; Corsaro, C.; Mallamace, D.; Vasi, S.; Vasi, C.; Dugo, G. The role of water in protein's behavior: The two dynamical crossovers studied by NMR and FTIR techniques. Comput. Struct. Biotechnol. J. 2015, 13, 33-37. [CrossRef] [PubMed]

33. Arrondo, J.L.; Goni, F.M. Infrared studies of protein-induced perturbation of lipids in lipoproteins and membranes. Chem. Phys. Lipids 1998, 96, 53-68. [CrossRef]

34. Legner, N.; Meinen, C.; Rauber, R. Root Differentiation of agricultural plant cultivars and proveniences using FTIR Spectroscopy. Front. Plant Sci. 2018, 9. [CrossRef] [PubMed]

35. Wang, J.; Zhu, J.; Huang, R.; Yang, Y. Investigation of cell wall composition related to stem lodging resistance in wheat (Triticum aestivum L.) by FTIR spectroscopy. Plant Signal. Behav. 2012, 7, 856-863. [CrossRef]

36. Nguema-Ona, E.; Vicré-Gibouin, M.; Gotté, M.; Plancot, B.; Lerouge, P.; Bardor, M.; Driouich, A. Cell wall O-glycoproteins and N-glycoproteins: Aspects of biosynthesis and function. Front. Plant Sci. 2014, 5. [CrossRef]

37. Barsberg, S.T.; Lee, Y.I.; Rasmussen, H.N. Development of C-lignin with G/S-lignin and lipids in orchid seed coats-An unexpected diversity exposed by ATR-FT-IR spectroscopy. Seed Sci. Res. 2018, 28, 41-51. [CrossRef]

38. Sain, M.; Panthapulakkal, S. Bioprocess preparation of wheat straw fibers and their characterization. Ind. Crops Prod. 2006, 23, 1-8. [CrossRef]

39. Siebers, M.; Brands, M.; Wewer, V.; Duan, Y.; Holzl, G.; Dormann, P. Lipids in plant-microbe interactions. Biochimica et Biophysica Acta 2016, 1861, 1379-1395. [CrossRef] [PubMed]

40. Gronnier, J.; Germain, V.; Gouguet, P.; Cacas, J.-L.; Mongrand, S. GIPC: Glycosyl Inositol Phospho Ceramides, the major sphingolipids on earth. Plant Signal. Behav. 2016, 11, e1152438. [CrossRef]

41. Mamode Cassim, A.; Gouguet, P.; Gronnier, J.; Laurent, N.; Germain, V.; Grison, M.; Boutté, Y.; Gerbeau-Pissot, P.; Simon-Plas, F.; Mongrand, S. Plant lipids: Key players of plasma membrane organization and function. Prog. Lipid Res. 2019, 73, 1-27. [CrossRef]

42. Bagińska, K.; Makowska, J.; Wiczk, W.; Kasprzykowski, F.; Chmurzyński, L. Conformational studies of alanine-rich peptide using CD and FTIR spectroscopy. J. Pept. Sci. 2008, 14, 283-289. [CrossRef]

43. Severcan, F.; Haris, P.I.; Press, I. Vibrational Spectroscopy in Diagnosis and Screening; IOS Press: Amsterdam, The Netherlands, 2012.

44. Abbas, O.; Compère, G.; Larondelle, Y.; Pompeu, D.; Rogez, H.; Baeten, V. Phenolic compound explorer: A mid-infrared spectroscopy database. Vib. Spectrosc. 2017, 92, 111-118. [CrossRef]

45. El Semary, N.A. The characterisation of bioactive compounds from an Egyptian Leptolyngbya sp. strain. Ann. Microbiol. 2012, 62, 55-59. [CrossRef]

46. Jensen, J.S.; Egebo, M.; Meyer, A.S. Identification of spectral regions for the quantification of red wine tannins with Fourier Transform Mid-Infrared Spectroscopy. J. Agric. Food Chem. 2008, 56, 3493-3499. [CrossRef]

47. Wolkers, W.F.; Hoekstra, F.A. Aging of dry desiccation-tolerant pollen does not affect protein secondary structure. Plant Physiol. 1995, 109, 907-915. [CrossRef]

48. Apaliya, M.T.; Zhang, H.; Zheng, X.; Yang, Q.; Mahunu, G.K.; Kwaw, E. Exogenous trehalose enhanced the biocontrol efficacy of Hanseniaspora uvarum against grape berry rots caused by Aspergillus tubingensis and Penicillium commune. J. Sci. Food Agric. 2018, 98, 4665-4672. [CrossRef] [PubMed]

49. Imamura, K.; Ohyama, K.-I.; Yokoyama, T.; Maruyama, Y.; Kazuhiro, N. Temperature scanning FTIR analysis of secondary structures of proteins embedded in amorphous sugar matrix. J. Pharm. Sci. 2009, 98, 3088-3098. [CrossRef]

50. Belton, P.S.; Gil, A.M. IR and Raman spectroscopic studies of the interaction of trehalose with hen egg white lysozyme. Biopolymers 1994, 34, 957-961. [CrossRef]

51. Stankovic, M. Innovative Platform Technologies for Stabilization and Controlled Release of Proteins from Polymer Depots. Ph.D. Thesis, University of Groningen, Groningen, The Netherlands, 2014.

52. Mouillon, J.-M.; Eriksson, S.K.; Harryson, P. Mimicking the plant cell interior under water stress by macromolecular crowding: Disordered dehydrin proteins are highly resistant to structural collapse. Plant Physiol. 2008, 148, 1925-1937. [CrossRef]

53. Sowa, S.; Connor, K.F.; Towill, L.E. Temperature changes in lipid and protein structure measured by fourier transform infrared spectrophotometry in intact pollen grains. Plant Sci. 1991, 78, 1-9. [CrossRef] 
54. Abdellatif, L.; Bouzid, S.; Kaminskyj, S.; Vujanovic, V. Endophytic hyphal compartmentalization is required for successful symbiotic Ascomycota association with root cells. Mycol. Res. 2009, 113, 782-791. [CrossRef]

55. Hubbard, M.; Germida, J.; Vujanovic, V. Fungal endophytes improve wheat seed germination under heat and drought stress. Botany 2012, 90, 137-149. [CrossRef]

56. Clarke, J.M.; McLeod, J.G.; McCaig, T.N.; DePauw, R.M.; Knox, R.E.; Fernandez, M.R. AC Avonlea durum wheat. Can. J. Plant Pathol. 1998, 78, 621-623. [CrossRef]

57. Vujanovic, V.; Goh, Y.K. Sphaerodes mycoparasitica sp. nov., a new biotrophic mycoparasite on Fusarium avenaceum, F. graminearum and F. oxysporum. Mycol. Res. 2009, 113, 1172-1180. [CrossRef] [PubMed]

58. Goh, Y.K.; Vujanovic, V. Ascospore germination patterns revealed ascomycetous biotrophic mycoparasite specificity to Fusarium hosts. Botany 2010, 88, 1033-1043. [CrossRef]

59. Vujanovic, V.; Goh, Y.K. Sphaerodes mycoparasitica biotrophic mycoparasite of 3-acetyldeoxynivalenol- and 15-acetyldeoxynivalenolproducing toxigenic Fusarium graminearum chemotypes. FEMS Microbiol. Lett. 2011, 316, 136-143. [CrossRef] [PubMed]

60. Fischer, E.R.; Hansen, B.T.; Nair, V.; Hoyt, F.H.; Dorward, D.W. Scanning Electron Microscopy. Curr. Protoc. Microbiol. 2012, CHAPTER, Unit2B.2. [CrossRef]

61. Schindelin, J.; Arganda-Carreras, I.; Frise, E.; Kaynig, V.; Longair, M.; Pietzsch, T.; Preibisch, S.; Rueden, C.; Saalfeld, S.; Schmid, B.; et al. Fiji: An open-source platform for biological-image analysis. Nat. Methods 2012, 9, 676-682. [CrossRef] [PubMed]

62. Toplak, M.; Birarda, G.; Read, S.; Sandt, C.; Rosendahl, S.M.; Vaccari, L.; Demšar, J.; Borondics, F. Infrared Orange: Connecting Hyperspectral Data with Machine Learning. Synchrotron Radiation News 2017, 30, 40-45. [CrossRef] 